\title{
The Study of Sociological Changes of Relationship with the Opposite Sex among Iranin Youth
}

\author{
Dr.Ali Ghanbari barzian \\ P.H.D in sociology A.S.Profssor, Faculty of human science Department, Sociology University of Isfahan
}

\begin{abstract}
The changes in Iranian society cause the undermining of the traditional pattern of relationship with the opposite sex and it has been replaced by some modern patterns, and in the meantime the role of family has become deemphasized. The results of this study paper, which used secondary analysis method indicated that data from various studies suggest that 36.2 percent of youth have a girlfriend or boyfriend and 63.8 percent have girlfriend or boyfriend, while 33 percent of youth were studied willing to establish friendly relationships with the opposite sex...the percent of new traditionalists is more than the other types, among the sample of girls, new traditionalists occupy the first rank and modernists(though with the difference of three percent) are ranked second. According to the given definition, modernity is more observable among boys.
\end{abstract}

Keywords: relationship-sexual identity-relationship with the opposite sex-typology.

\section{INTRODUCTION}

The revolution of Iran was a sub cultural Victory of the Islamic revolution, which is mentioned as revolution of values, suggests that before being described as political or economic, the nature of the Islamic revolution is assessed culturally. Therefore it is expected that regarding the historical contexts and ideological and cultural aspects, youth's developments be in line with the acquisition and internalization of Islamic and revolutionary values. Although in the beginning of revolution and during the war period this exception was met to a large extent, playing an active role in the victory of revolution, and keeping up their efforts, youth stabilized the pillars of the regime. But after the war period a generation of youth grew that faced the gap between physical-mental maturity and economic-social, on the other hand, now more than twenty seven years have passed since the triumph of the Islamic revolution, and in the third decade of revolution, an important structural change can be seen in the social system. Iran's society with low literacy has become an educated society. Illiteracy rate has reached by 15.6 percent. The real education coverage rate for children aged 6 to 10 years old has reached by 98.7 percent. Higher education system in the country has progressed significantly, and university population has had significant growth. Women make up significant portion of population studying in universities. More girls are accepted in higher education levels; to the extent that up to $72 \%$ of those who are admitted in university entrance exam are dedicated to girls who are mostly single. On the other hand, marriage conditions and opportunities are not perfect and suitable in society, which is the outcome of Iran in the era of modernization. These conditions resulted in creating and spreading of some kinds of disorders in girl-boy relations in the university medium and it has concerned the cultural managers. On the other hand, heterosexual orientations one of the most important needs and instincts of human ensures the survival of the human species. The sexual instinct appears in puberty with the opposite sex inclination and it means an innate, psychological and physical desire which makes one move in a certain way and leads to sexual behavior. Social role and sexual role have some aspects in common which they are more highlighted in the academic environment. Social role means that what role one has in the social system and how he should behave to meet the needs of society. On one hand, academic environment ensures youth that they can play roles, and then they look for desirable and acceptable mechanisms. Continuity and necessity of sexual behavior and sexual role has important psychological and social outcomes for the individual, society as well as for the academic environment, which can be very influential in making the important choices in life. Psychological and cultural consequences will also transfer into the institution of family, and lead to modelling terms of sexual role and behavior. The age of university students is started from 18 years, which is the age of outpouring of feelings and emotions, and continues until age 30 and above it. In these ages although some youth get married but there is still inclinations in them. This study is to identify trends and changes while determining the kind and degree of heterosexual orientation.

Main and sub questions of the study: The main question of this study is: How changes in heterosexual relationships occur? 
1- How is the process of changes in the degree of relationships with the opposite sex?

2- How much is the degree of heterosexual orientation at different levels?

Objectives of study The main objective of this paper is to study changes in heterosexual relationships in Iranian society.

1- Studying the degree of heterosexual relationships at different levels.

2- Examining youth view toward the heterosexual relationships, with separation of men and women at different levels.

Methodology Using secondary analysis, the paper deals with processes and changes of this issue 1999-2013. For this purpose, five researches done during these years have been made use of, which are as follow:

$\square \square$ JavadiYeganeh, Mohammad Reza, survey of young youth in Tehran about heterosexual relationships, IDO, 1999

Hajilori, Ali, examining boy-girl relationships in universities, 2006

$\square \square$ Ghanbari, Ali, examining the status of heterosexual relationships in universities, 2009, Cultural Department of Ministry of Science Research and Technology

Ghanbari, Ali, study of behavioral and ethical disorders in Iranian students, 2011

Hashemi, Syed Ziya and Ghanbari Ali, typology of students' patterns of heterosexual relationships in universities of Tehran, 2006

Background of semantics of sexual behavior Various sciences, biology, psychology and anthropology have different meaning of sexual behavior. Biologists define sexual behavior as "any behavior increasing the chance of combination of sperm and egg is called sexual behavior" (Hyde،1998 ،3). In this definition the emphasis is laid on the function of reproduction. The definition, given by biologists, of sexual behavior and inclination towards the opposite sex started with the discovery of sperm by Anton van Leeuwenhoek and his colleague John Ham (same, 4). Psychologists have defined sexual behaviours "any behavior which induces sexual arousal and increases chances of reaching an orgasm" (same, 4). Hunt carried out a research in 24 states of the United States, in which 982 men and 1044 women participated. Of this population, 90 percent were white, 10 percent black, 71 percent married, 25 percent single and 4 percent had got married long before. In the results of Haunt's research the increase in premarital sex in the United States indicates that at that time, the community of the United States had more sexual behavior freedom than in the past. (Same, 39). These studies along with the reedition of Greeks' researches and Romans' manuscripts became the standard text of the newly established schools of medicine, and revived the anatomical investigations in the 16th, 17th and 18th century. Even today the names of Fallopian tubes, Bartholdi's glands and Cowpers glands recall the first flowering of modern anatomy and new findings in sexual anatomy of human. The Age of Enlightenment has brought up various and increasingly secular issues about sexual code of ethics, and also brought about the first public and private sex education programs, and classification and new evidence on sexual behavior. In 19th century new concerns about the increase in number of sexual neurotic youth and moral-corruption have been added to the concept of sexual inclinations. Finally at the beginning of the twentieth century, innovative practices Havelock Ellis, Sigmund Freud and Ivan Bloch founded investigations on sexual problems as a legal work. Scientific conceptualization and doing research activity to understand and realize sexual issues for the first time raised by Ivan Bloch dermatologist in the University of Berlin (1872-1922) who had also created a new term for that'sexualwissenschaft'. New concept of sexual behavior ology (meaning theoretical study of sexual issues) can be distinguished from the old concepts of sensual behavior ology. Sexy writings such as the book 'kama sutra' by vatsavayana, and other Indian love manuscripts and their new western likes such as the book 'Ideal Marriage' by van de Velde, or 'Sexual Pleasure' by Comfort all are trying to lead the reader to an imaginary pleasure. Forty years later, this classification was modified by Krafft-Ebing, in another book with the same title. In this period of sexual behavior ology which was the introduction of new sexual studies, only those youth who were considered as patient were being studied. (Javadi, Yeganeh, 2007). In this period, symptoms of a patient's disease were carefully written and usually the disease was attributed to moral corruption. Expanding of such an attitude only could have originated from outside the scope of medicine and biology which was later discovered. As Ivan Bloch's work proved, this view originates from two sources of history and anthropology which have been neglected. Because of his many studies, Bloch knew that most probably immoral sexual behaviors always have existed in most parts of the earth, among the early as well as modern civilizations. Therefore he concluded that medical perspective on sexual behaviors (sexual psychopathies) and finally in the early years of twentieth century he offered the sexual corruption theory through a research which he was carrying out about sexual satisfaction. 


\section{A- Sex or Sexuality}

This concept is used in two senses, the first meaning relates to sensual activity which leads to pleasure or reproduction and the second meaning involves the concept of sexual biology. Existence of female chromosomes and ovaries are very important to determine the sexuality of women, however having the feeling of being a womanise more important for being a woman, as the male chromosomes and testes are essential for determining male sex; although existence of these features do not necessarily show the feeling of being a man (Lindzy \& Thompson, 1988:417), having male psychological characteristics reveals the sense of masculinity and leads to the distinction of feelings of being a man and woman.

\section{B- Sex identity}

Gender identity is a case of this or that, youth believe that humans are either man or woman, still youth differ considerably to the degree that they perceive themselves as man or woman, as well as in terms of all their feminine or masculine features and it forms their sexual conventional pattern. In terms of gender self-concept, youth with high degrees of masculinity believe that they have many traits, interests, preferences and skills which society associates them with being a man. On the contrast, youth with high degrees of femininity believe that they have many traits, interests, preferences and skills which are associated with being a woman. (1997 Taylor, Sears). In recent times, some psychologists have challenged this one-dimensional view of psychology towards masculinity and femininity, for instance they have raised the theory that some youth see themselves as having both masculine and feminine features. In considerations about the growth of men and women and identity formation, the notions of gender identity and gender roles have crucial roles. Gender identity is an individual's sense of sexuality and the meaning which is induced by it. This concept has a basic role in growing the sense of self. Sexual identity refers to the following variables, "internalized feeling of being man or woman, being aware of biological sexual relations which include psychological traits associated with it".

\section{C- Role of sex and Social role}

Sex role is a kind of cultural expectation which determines how men and women communicate with each other and also identifies individuals' activity based on their values and interests (Cast ells, 418, 1988). Gender role is linked with gender identity. Individual's learning's is the main factor in acquiring the proper sex role. Sometimes, sex role and gender identity conflict. An individual may have sexual relations with a member of the same sex, yet prefers clothing, hairdressing or other characteristics of the opposite sex. Even an individual may have sexual relations with a member of the opposite sex and according to situation takes the behavioral characteristics of the same sex.

Theoretical framework In Theoretical Foundations, we will investigate the most important theories that explain the issue of relationship with the opposite sex. So, first we propose the concept of relationship and psychology of relationship and name its variantsand then bring up the related theories.

Definition of relationship and its variants Relationship means a kind of behavioral and psychological involvement with any particular object or person (Ahmadi, 2007, 9). When human's mind gets busy in something and invests emotionally in it and consequently shows behaviourism order to influence on it has set relationship with that object. This is a behavioral and psychological relationship. When the subject of this relationship is a person of the opposite sex, especially before marriage, then the matter is boy-girl relationship. Relationship between girls and boys involves expressing interest, involvement and dependence and can be extended from face to face meeting to an open and unrestricted relationship. According to norms and values, any society chooses a point on this spectrum as starting point of abnormalities. Deviation from this point will cause abnormalities and so many different social and psychological consequences. Therefore, relationship with opposite sex or boy-girl relationship includes emotional relationship as well.

Based on the above explanations, the fundamentals and principles of psychology of communication can be summarized in the following cases:

A- Considering personality traits and psychological and social needs of audiences.

B- The content of the message in the communication process such as establishing a friendly relationship or exchange of emotions and other things.

C- Situations and conditions for establishing a relationship like, park, college, café.

D- The way of establishing a relationship and conveying massage, the most effective way to communicate the message is a way in which the cognitive and emotional domains of addressee is affected seriously. Such as writing a note, writing a letter, and giving books as gift and etc. 
E- Considering the characteristics of ethic reference patterns and groups (same: 4 to 12). On this basis, if a behavior is common in an environment and contains a high frequency others will also encourage to perform that behavior.

Relationship with the opposite sex is one of the different types of interpersonal communications which according to the given definition its components are as follows:

1- Gender differences in the parties of a relationship; therefore this is not a one-side relationship and both sides either girls or boys, have an active role in this relationship. Thus relationship establishers are at least one boy and one girl, enjoying functions based on gender and sexual potency.

2- Apart from cultural purposes, the purpose of this relationship is educational, economic, friendship, love, intimacy and empathy as well. However with sexual affection and in sexual level.

Relationship with opposite sex can be at least defined in terms of three components and distinguished from the other forms of human communications. The thing which separates one relationship from another is nature and components of that relationship. According to these factors, friendship with opposite sex is also distinguished from other types of relationship. In this relationship, the desired message is "affection", "Intimacy", "love", "seeking friendship", etc. relationship with opposite sex may results in functions such as employment, marriage, building confidence, gaining social status, psychological base, or social and psychological damages(Ahmadi, 2000: 116-118). Thus, relationship with opposite sex means relationship between two humans of different genders, having sexual potency, which is established with the purpose of exchanging love, intimacy, affection. And it's exchanged between individuals through direct or indirect conversation (on the phone, correspondence, movement and physical contact). In their communications, youth create concepts. Relationship is not just a matter of exchanging words or non-verbal behaviors but it's a meaning which is created as a result of the interpretation of each other, because words and behaviors are not meaningful in themselves, but they are symbols which should be interpreted and take meanings to match their meanings with each other gradually and reach a common understanding about their feelings and issues. In sociology of communication, this model is known as Lass well's model of communication. According to this communication model, in establishing a communication considering elements like, when, where, how and with which tools are essential and important. Regarding the patterns of communication with opposite sex, Robert Sternberg paradigm should be pointed out. Robert Sternberg proposed a triangular model of communication with the opposite sex

\section{a) Intimacy or belonging b) Lust and Desire c)commitment}

In his view, intimacy or belonging involves feelings of closeness with a person or persons. Lust refers to sexual attractions, and commitment means a willingness to continue the relationship (Khosravi, 2004, 195). Researchers underline that self-exposure is an important element in establishing the relations and this feature is more common among girls than among boys. It seems that boys' and girls' expectations of friendship and relation differ. Boys look at relationship as a tool; however girls consider friendship, deep, meaningful and stable relationships (same, 205). Researchers examined students for some time and concluded that apart from the number of friends, the amount of time which students of both sexes spend on their friendship is the same, but the boys like to do activities with their friends at the times that they are together. The difference between male and female attitude towards the issue of relationship is not seen only among girls and boys, but it is a continuous phenomenon which will involve them in later stages, in young and throughout middle age. Unfortunately, some women particularly those who have not built a strong marriage, and while living with their spouse or after separation from him or his death are ready for relations with other men suffer the damage repeatedly. In hopes of receiving affection and positive emotions from man, woman gets close to him and submits her to him but man after satisfying his sexual needs leaves the woman. Such men sing romantic songs when their sex drive increases and these songs deceive woman, romantic words and expression continue until the sexual need of men is met, as soon as this need is met there will be no romantic expression, even aggressive and derogatory words are substituted. Sociological theories Theory of Individualism and its effects in emotional relationship. Mechanism of modernity in the West for crushing whatever is rigid and hard has been the principles of Liberalism and Capitalism. Freedom and individual rights, two fundamental principles of Liberalism and Capitalism, form the essence of western modernity. The thing which guaranteed and justified the individuality of western human in the institution of family, in the modern period, was the appearance and spreading of the concept of "emotional or romantic love". In the modern period, romantic love was substituted for the social, political, economic and cultural interests and criteria so that two youth join together as a couple. Some experts define the romantic love as a purely European phenomenon; they believe that only in Europe for the first time love was considered as the main reason of marriage in public level and we don't know any other community that is so. One of these experts is British sociologist Anthony Giddens. Giddens distinguishes between two kinds of love: Erotic and emotional love. In emotional love, the elements of transcendental love 
overcome the sexual passion; this is the feature which distinguishes it from the erotic love. Erotic love is a universal phenomenon, but Giddens believes emotional love is a modern phenomenon and modernity took shape in Europe, then it can be concluded that emotional love is a European phenomenon (Giddens, 1992, 38). The recent structural sociologists' perspective is against the ideas of Durkheim; they believe that society itself creates the conflicting demands by making a discrepancy between its approved goals and ways available for achieving it. In this way, we see that they present a more limited meaning of the concept of abnormality from the view of Durkheim. Merton, an American sociologist can be named as one of the pioneers of this path, who by publishing a short article entitled "Social Structure and Anomie" was the founder of this method of explanation. Anyway, the explanation is called by different names such as the theory of structural pressure (pressure), motivational theory, anomie theory, and the theory of social disorganization, here anomie is considered as a pressure that is laid on youth when the accepted aims and norms in society are in conflict with the existed social facts (Giddens: 140), the vague situation of an individual's connection with the society in which norms are lost or they are weak or they are in contrast. A situation which takes the common values and aims from the members of a society, and it makes them not to find behavioral guides and clear ethical guidelines (Sedigh, 2006, 173). So, it can be seen that in this explanation, aberration is the result of inadequacy in culture and social structure of society; a situation which is sometimes interpreted as a gap and distance between the available instruments and socially accepted goals. 30.3 percent of samples friendly relationships with the opposite sex, and 69.7 percent of samples don't have relationship with their opposite sex. Students of Tehran and Sanandaj have more relationship with the opposite sex than the students of other states. 38 percent of students of Tehran, 30 percent of students of Sanandaj and Isfahan, 24 percent of students of Kerman and Tabriz, and 25 percent of students of Ahvaz have experienced friendship with their opposite sex. 31.9 percent of statistical populations willing to establish relationship with their opposite sex. Students of Tabriz, Tehran and Sanandaj more than the students of other states are willing to have relationship with their opposite sex. 35.9 percent of students of Tehran, 35.6 percent of students of Sanandaj, 37 percent of students of Tabriz and 33.6 percent of students of Mashhad are inclined to establish relationship with their opposite sex.

\section{a- The applied method}

\section{CONCLUSION TYPOLOGY}

Samples being studied can be divided into different types or kinds. In terms of various features in relation with the desired phenomenon, youth ascribed to each type are similar to each other, to the extent that we can say there is an agreement among them rather than disagreement. Also, youth of the same type in addition to the theoretical or attitude similarities, in terms of behavior, maintain samples which don't differ in nature and are greatly similar in appearance. According to the same attitude or behavioral methods of each type and significant differences of each type with the other one, each type can be defined as a subculture, or at least known as a pseudo subculture. Totypologize the subjects, the tool which is used is a matrix, variables are in its rows and types in columns, and in each cell the state of every type is determined with respect to each variable. Only those variables can participate in typologic analysis, which have a strong or rather strong correlation, whether positive or negative, with each other. Weakly correlated variables impair typology or make it impossible. Gender as a sociological variable and not a biological one is an important factor in cultural (behavioral and attitude) differences. In other words, differences in beliefs, values and learned behaviors of boys and girls during the years of socialization particularly the first years of life, has an important role in creating gender differences in terms of different social variables, cultural, political, ... . The percentages of boys and girls grouped in each of the types are different significantly. The percentage of girls in traditionalist type is more than the percentage of boys' sample. In general, the percentage of new traditionalists is more than the other types, among the sample of girls, new traditionalists occupy the first rank and modernists (though with the difference of three percent) are ranked second. According to the given definition, modernity is more observable among boys. Sexual desires of boys rather than girls' show more increase.

\section{REFERENCE}

[1]. Rubin, Hogoot, (2001) university and Sexual Revolution, Chicago University Press

[2]. Seid man Stuart N. (1995). A Review Article of Sexual Behavior in the United States Graw-hill Newyork.

[3]. Taylor, and Aspence and Rooger, (1999), Sex Myths, New School New York

[4]. Waite.linda,(2002), Man and Woman General Happiness and Sexual Satisfaction, Chicago university.

[5]. Ohadi, Behnam. (2007), the Sexual Tendencies and Behaviors of Human Beings, SadeghHedayat Publications.

[6]. JavadiYeganeh, Mohammad Reza. (1998), Interviewing the Youth of Tehran on the Sexual Relationships with the Opposite sex, Islamic Propagation Organization.

[7]. Golzari, Mahmood. Typology of Sexual Relationship with the Opposite Sex in State Universities, Ministry of Science, research and Technology

[8]. Anthony Giddens, (1999) Consequences of Modernization, Translated by Mohsen Salasi, Nash Publications 
[9]. Ghanbari, Ali. (2009). A Survey of Conditions of Sexual Relationship with the Opposite Sex in Universities, Cultural Deputy of the Ministry of Science, Research and Technology

[10]. Ghanbari, Ali (2011), a Survey of the Behavioral and Moral Abnormality of the Students in Iran. 